\title{
WMU journal of marine affairs special issue
}

\author{
Ilias D. Visvikis ${ }^{1} \cdot$ Mary R. Brooks $^{2}$
}

(C) World Maritime University 2015

This special issue consists of selected papers presented at the International Association of Maritime Economists (IAME) conference in Norfolk, Virginia, 15-18 July 2014. They cover issues of considerable importance in the maritime industry and reflect new developments in the industry of interest to shipping lines, the ports that serve them and governments seeking to bring policy in line with modern shipping practice.

More specifically, the first four papers discuss the environmental aspects ranging from environmentally-friendly technologies in shipping and designing for emissions allocation in container shipping to the use of LNG-fueled vessels in China and the development of LNG bunkering facilities in North European ports. These four papers indicate the significant interest in new technologies, emissions calculations, and the greening of the industry and are particularly relevant for readers interested in what the future may hold.

Those developing new technologies have long considered how to improve technology uptake and ensure that technologies become more widely adopted, eventually becoming mainstream. The first paper titled Towards understanding the stepwise dissemination of shipping technologies suggests that adoption does not follow a logical and incremental path but rather a stepwise one where shifts in adoption are significant and abrupt. It provides food for thought to those seeking to understand the conditions by which technologies are adopted, and the concerns that face those with new technologies and hoping for their adoption. There are many in the industry that believe that the impacts should be obvious and that the uptake of new concepts will be logical and predictable. This paper, by arguing for an alternative adoption trajectory, provides insights into what is more likely to happen. It suggests that those with new technologies in development might consider building a program that enhances the probability of

Ilias D. Visvikis is a Professor and Director, Executive and Professional Education, World Maritime University Mary R. Brooks is a Professor Emerita, Rowe School of Business, Dalhousie University.

Ilias D. Visvikis

iv@wmu.se

1 World Maritime University, Citadellsvägen 29, 20124 Malmö, Sweden

2 Rowe School of Business, Dalhousie University, Nova Scotia, Canada 
acceptance and adoption by focusing on existing technologies, and their supporting structures, so that they can identify what will encourage interest in and ultimately adoption of the new technology. The role of data in feeding the adoption process is highlighted as critically important but underestimated by those who collect it.

Following the previous article, Rational scheme designs for emission allocation in container shipping continues the environmental theme. The purpose of emission allocation is to distribute the impacts of emissions from a transport network to different cargo levels in order to ensure that those who are charged for the costs of emissions are those who incur them. The paper proposes and evaluates alternative allocation schemes for assigning the emissions from container ships. The paper examines the assignment of emissions impacts on various bases (different cargo aggregation levels), such as sailing legs, individual containers, and specific cargo types within a container. The authors utilize a case study on how these schemes can be applied to an existing container shipping line, proving a strong contribution in the area, and moving the debate from theoretical to practical implementation. Out of the several investigated methods, they found that the "total transport work" method can be used regardless of the variations in distance travelled and vessel speed. More specifically, at the container level, they argue that the "volume-based" method should be used to allocate emissions to each type of container when the number of standard containers is dominant. In terms of the allocation of emissions at the cargo shipment level, the "value-based" method should be used to ensure the consistency of the calculation for the same type of cargo loaded in the containers with different limitation factors. Overall, the paper provides a significant insight for shipping companies and their clients in order to achieve more accurate assignment of emissions to monitor, with the aim to improve their environmental performance. We are sure that this is not likely to be the last paper on this critical topic faced by shipping lines and hope to see more of this type of research in future.

During the last few years, liquefied natural gas (LNG) has received much attention and interest as a clean and efficient emerging marine fuel. It has garnered attention as a possible solution to ship-induced environmental issues and increasingly rigid emission restrictions. The third paper, titled Emerging LNG fueled ships in Chinese shipping industry: A hybrid analysis on its prospects, raises the argument that only a few LNG fueled ships are in operation in China, with the majority of those on inland waterways like the Yangtze River. The focus of the paper is to investigate and analyze the development prospects for LNG fueled ships in inland waterway transportation in China. The authors use a SWOT analysis in combination with an analytic hierarchy process (AHP). The main results indicate a growing trend is likely for the use of LNG fueled ships in Chinese shipping industry. For strategic development, the authors recommend that stakeholders should not only focus on the opportunities and advantages of LNG fueled ships, but also mitigate the threats and overcome weaknesses for the industrialization of LNG fueled ships in China. Overall, the results of the paper offer good insights into the prospects for LNG bunkering in the Chinese shipping industry; at the same time, the paper provides information to stakeholders and policymakers for decision-making on the development of LNG fueled ships.

Continuing with the energy and environment theme, the fourth paper titled The role of port authorities in the development of $L N G$ bunkering facilities in North-European ports argues that the lack of bunkering infrastructure in most seaports is a significant barrier to the adoption of LNG as a marine fuel. Its use as a marine fuel is just one new 
energy option that promises a better environmental outcome for our planet and a positive economic one for industry. Based on a study of eight public port authorities in North Europe, the paper analyzes the role of port authorities in the development of LNG bunkering facilities and in promoting LNG use. The importance of the port in facilitating the discussion and building the local community support for LNG adoption is explored; it is noteworthy that all eight ports studied introduced incremental port tariff discounting and/or other incentives to support the adoption of LNG as a marine fuel for ships calling the port. The paper outlines opportunities that have been exploited by ports in North Europe and that might be more widely adopted outside the region, as ports contemplate what they may do to support the shipping industry as it attempts to improve its environmental footprint. There are significant managerial suggestions for ports in this paper that industry would do well to consider.

The next two papers have a stronger policy bent and will be of interest to policy makers as well as those in industry. The fifth paper in this issue presents port security regulation compliance issues and will be of interest to those concerned with public safety and ports. The sixth paper explores the key issues of connectivity in the Greek coastal shipping market and how it may be restructured. Its focus on gaining community support for new policies and strategies makes a considerable contribution to the maritime policy field.

Making lemonade out of lemons: Port operators' perceptions of their port security regulation compliance examines best practices in port security strategies via an exploration of how ports address and manage port security issues. Using the well-established Resource-Based Theory as a framework for discovery about strategies that add value, the authors evaluate the perceptions of port managers in both Europe and North America with respect to how port security impacts their port's competitiveness. In a research field like port security, where responsiveness to survey instruments is likely to be reluctant at best, the authors focus on perceptions that provide insights to help all port managers chart the path forward and understand where value is created for each particular port. The paper particularly notes differences between US and European ports and terminals. The way assets are deployed and managed, in the case of US ports and terminals, is perceived to be most effective in creating business value. On the other hand, EU port and terminal operators perceive that business value can best be gained via the deployment and management of physical structures, like perimeter barriers, for example, but for ongoing management security resources, only documentation and security reports contribute positively to building value. For those in the port sector attempting to understand the fragmented world of port security options, this paper does indeed help the port security officer "make lemons into lemonade".

The authors of the sixth paper, titled Restructuring coastal shipping: A participatory experiment, use the Delphi method to explore the key issues of connectivity in the Greek coastal shipping market and the possible means by which it may be restructured. To be accepted, maritime policy cannot always be just fashioned by policy-makers and implemented without regard to impacts on communities dependent on the industry. The paper considers alternative transport networks for connecting Greece's islands and evaluates the way by which connectivity in island states is assessed. By exposing conflicts and options through a facilitated process, building consensus for various options can invite the development of solutions that will gain the support of key industry players. While the two-step process involved in this research did not use the same instrument with the same respondents in its second phase, the paper presents an 
approach that will be increasingly needed as citizens come to grips with doing more with less in a resource-constrained world. The authors have begun to outline the process that ports, shipping lines, and governments will need to consider as the role of social license becomes ever more critical in building successful outcomes well beyond those of Greek coastal shipping. The lessons from the sixth paper will also be of interest to port managers who have read the fifth paper, as gaining acceptance for policy and industry change is becoming ever more difficult.

The next three papers take the maritime policy topic to a finer focus that of the seafaring labor market and in particular move towards an explicit focus on retention in the industry. This is one of the most important issues facing shipping in the future.

The seventh paper, titled Maritime policy and the seafaring labor market, investigates the current lack of merchant marine officers for the continuously expanding worlds' fleet and evaluates the impact of regional maritime policies on the seafaring labor market. This is a challenging research issue for the whole maritime industry due to the widely varying maritime labor policies found in different countries. The paper provides a comparative analysis of the seafaring labor market in the Philippines, Poland, Germany and Brazil and discusses the general maritime labor policies found there. The authors argue that the focus on these countries enables a comparative analysis of maritime labor as a factor of production in an exporting market, an importing market, and a closed market. They argue that crew costs, restrictions on the nationality of employed seafarers, and quality of maritime education and training play significant roles.

Exploring the range of retention issues for seafarers in global shipping: Opportunities for further research continues the theme. This paper examines the literature on seafarer retention and draws conclusions of relevance to the industry and its managers about the attraction and retention of talent in the industry. Many transport sectors face issues of retaining talent; for example, the trucking industry is in very dire circumstances in many countries, as drivers age and the attrition rate are higher than the replacement rate. Therefore, the seafaring industry is not alone. Thirty years ago, seafaring was considered a way to see the world and earn a living that could support a family at home. Now vessels have reduced port time, the glamour of the industry has been lost, and retention has become a critical factor in the success of most shipping businesses. However, retention of talent is a topic that is seldom explored. While this issue is of concern across all transport modes, it has been made more serious by recent efforts in the maritime sector to "punish" those who cause maritime accidents or incidents, as seen recently in the Costa Concordia decision. This paper provides a solid overview of the state of the industry, its challenges with seafarer retention and contributes to our understanding of this particular sector of the industry and what must be addressed. The long-term strategy of labor progressing from "time aboard ship" to "time ashore" over a maritime career is noted; in this industry, career progression is an important element to be planned for, and this paper makes that longer-term need very clear. While not stated explicitly, the paper calls for further research, for industry interviews to be conducted and for greater qualitative data to be collected to help articulate the range of retention issues that are needed in the industry. To adequately explain the attrition process among seafarers is a first step in ensuring that we all understand what is needed to make the labor market for shipping work better. The authors also propose research to understand the drivers of job satisfaction and we could not agree more. As is the case in many industries, the career of seafaring is not a single 
"at sea" life stage but a progression over a lifetime where each stage in the career builds to the next. This research we hope will foster further investigation into this very important industry factor of success.

Continuing in the seafaring labor theme, the ninth paper, titled The role of communication to the retention of seafarers in the profession, examines the availability of and access to communication facilities on board ships as an important factor that contributes to the retention of seafarers. The authors conduct a survey of more than 500 seafarers requesting them to respond to a questionnaire, with the aim of collecting information on various work-related issues and on seafarer job satisfaction, research proposed by the previous paper. Communication services and their availability on board ship, and the type of access to communication facilities and the cost of access for the seafarers receive particular emphasis in the survey. Results demonstrate that respondents consider the separation from family and the inadequate communication with family and friends while at sea as the most important issues hindering retention in the profession. Furthermore, results indicate that inadequate communication with family and friends is the single most important reason leading seafarers to abandon the profession. The authors argue that the findings of this paper are not only important in tackling the issue of retention of seafarers already employed in the industry, but also contribute to generating strategies for improving the image and awareness of the maritime industry.

The last paper in this special issue is not a natural fit with the general theme of new environmental technologies and maritime policy but makes a contribution to the way shipping companies may examine their options in future. The paper, titled Fuzzy time series forecasting of bunker prices; Nonstationary considerations, investigates the commercial aspect of forecasting bunker fuel prices. The accurate forecasting of the level of bunker fuel prices is an important topic in the maritime industry, as fuel typically constitutes the largest component of voyage costs. The adverse fluctuations of the bunker prices influence speed-, routing-, and market-related decisions taken by shipping companies, and consequently, the financial outcome of a chartering strategy. Therefore, the paper investigates the applicability of fuzzy time series forecasting techniques for the prediction of bunker fuel prices. Weekly time series of bunker fuel prices in four major world ports (Rotterdam, Houston, Singapore, and Fujairah) are examined to assess the forecasting performance of the fuzzy models, giving an international coverage of the largest bunkering ports. The methodology employs four error-measures as an evaluation criterion to compare the performance of the competing forecasting models. The main results indicate that all four forecasting error-measures reach their minimum value at the same point, which gives closer forecasts to the actual values. Overall, the efficient forecasting of bunker fuel prices can lead to accurate estimates of bunker price volatility and result in better bunker hedge ratios, therefore risk management (hedging) strategies and better financial outcomes for shipping lines hedging fuel prices. As opposed to focusing on what is new in future or what changes might be made to the maritime policy climate, this paper focuses on how existing operators may survive profitably through attention to detail in their bunkering strategies.

This special issue has presented ten papers from the IAME 2014 conference, and each has made a contribution that will be of interest to policy makers, to shipping lines, and/or to ports. We are pleased to have been asked to undertake the management of this special issue and hope that you enjoy the very significant research contained in it. 